$\$$ Research Square

\title{
Defining microbiome communities in banana (Musa spp.) with and without symptoms of Fusarium wilt
}

\section{Manoj Kaushal ( $\nabla$ M.kaushal@cgiar.org)}

International Institute of Tropical Agriculture https://orcid.org/0000-0002-0229-612X

\section{Rony Swennen}

International Institute of Tropical Agriculture

George Mahuku

International Institute of Tropical Agriculture

\section{Method Article}

Keywords: mfert

Posted Date: January 17th, 2020

DOI: https://doi.org/10.21203/rs.2.17013/v2

License: (1) This work is licensed under a Creative Commons Attribution 4.0 International License.

Read Full License 
The authors have withdrawn this preprint from Research Square 